\title{
LA CONSTRUCCIÓN DEL LITORAL ARGENTINO A FINES DEL SIGLO XIX. LAS CARTAS DE VIAJE DE GABRIEL CARRASCO
}

\author{
The construction of the argentine littoral at the end of nineteenth century. The \\ Travel letters of Gabriel Carrasco
}

María G. Micheletti*

\section{Resumen}

En 1888 el estadístico rosarino Gabriel Carrasco, comisionado por la organización del Censo de Agricultura y Ganadería de la República, realizó un recorrido por las provincias de Corrientes y Entre Ríos, los territorios nacionales de Chaco, Formosa y Misiones, y el Paraguay. Poco después, reunió y publicó las impresiones que le suscitaron los parajes visitados en un libro titulado Cartas de viaje (Buenos Aires, Peuser, 1889). El género epistolar fue el elegido por Carrasco para hilvanar los datos recolectados, las descripciones geográficas y las referencias históricas con sus concepciones sobre la Modernidad, en un texto en el que las preocupaciones del presente y la fuerza programática del futuro parecen imponerse a las representaciones que se vierten sobre el pasado.

El objetivo de este artículo consiste en indagar la idea de región litoral que construye Carrasco a través de sus Cartas, procurando determinar los principales rasgos que contribuyen a dotar de identidad y sentido a esa comunidad imaginada.

$<$ Gabriel Carrasco $><$ litoral argentino $><$ historia y memoria $><$ historiografía argentina $>$

\begin{abstract}
In 1888 the statistical Gabriel Carrasco, commissioned by the organization of the Census of Agriculture and Livestock of the Argentine Republic, toured through the provinces of Corrientes and Entre Ríos, the national territories of Chaco, Formosa and Misiones, and Paraguay. Soon after, he collected and published his impressions of the sites visited in a book entitled Travel Letters (Buenos Aires, Peuser, 1889). The epistolary genre was chosen by Carrasco to baste the data collected, geographical descriptions and historical references with his conceptions of Modernity, in a text in which the concerns of the present and the programmatic strength of future seem to impose themselves to the representations of the past.

The aim of this paper is to investigate the idea of littoral region constructed by Carrasco through his Letters, trying to determine the main features that contribute to give identity and meaning to that imagined community.
\end{abstract}

$<$ Gabriel Carrasco $><$ argentine littoral $><$ history and memory $><$ argentine historiography $>$

\footnotetext{
* Investigadora Adjunta CONICET, Profesora Adjunta UCA, IH, UCA - IDEHESI/CONICET. mgmicheletti@conicet.gov.ar
} 


\section{Introducción}

En el año 1888, el abogado y estadístico rosarino Gabriel Carrasco realizó un recorrido por las provincias de Corrientes y Entre Ríos, y por los territorios nacionales de Chaco, Formosa y Misiones, e inclusive llegó al Paraguay. Las impresiones y relatos que le suscitaron los parajes visitados, dados a conocer en primera instancia a través del diario La Prensa, fueron reunidos y publicados al año siguiente en un libro titulado Cartas de viaje por el Paraguay, los territorios nacionales del Chaco, Formosa y Misiones y las provincias de Corrientes y Entre Ríos.

Este artículo constituye una aproximación a la idea de región litoral que se construye a través del discurso epistolar de Carrasco, y busca indagar las representaciones sobre el pasado que contribuyen a configurarla, así como las características que la distinguen de cara al futuro, por medio del análisis de una serie de núcleos problemáticos. Si se entiende a la región -en tanto que "espacio diferenciado"- como una "construcción política e identitaria", es decir, como una "comunidad imaginada", puede ponderarse hasta qué punto la literatura de viajeros - de la que son una expresión estas Cartas de Carrasco-, así como la toponimia, el discurso escolar, los discursos académico y político, la cartografía histórica, la iconografía oficial, la prensa y los medios de comunicación $\mathrm{y}$, en general, el conjunto de representaciones socialmente producidas con respecto a las regiones, "pueden constituir terrenos fructíferos para indagar sobre la producción de imaginarios regionales". ${ }^{1}$

El Litoral, como región histórica, había adquirido consistencia entre los siglos XVIII y XIX (Maeder, 1982: 17), y durante el período de las guerras civiles decimonónicas había alcanzado singular protagonismo a través del accionar y liderazgo de sus caudillos. Teniendo por núcleo a las provincias de Santa Fe, Corrientes y Entre Ríos - pero con unos límites difusos que se prolongaban hasta la Banda Oriental en la Liga de los Pueblos Libres de Artigas-, había conseguido perfilarse a principios del XIX como una región diferenciada al distanciarse de la política porteña y erigirse en defensora de las autonomías provinciales frente al creciente centralismo ejercido desde Buenos Aires.

Este proceso de construcción de la región durante la primera mitad del siglo XIX ha dado lugar a interesantes estudios, como el de José Carlos Chiaramonte, quien ha profundizado en el rol cumplido por Corrientes como promotora de la Liga del Litoral y como la más firme opositora a la política de Buenos Aires. Un aporte significativo de Chiaramonte ha consistido, sobre la base del cuestionamiento al supuesto de la nación preexistente, en haber resaltado la preeminencia de las provincias

\footnotetext{
La perspectiva conceptual que considera a la región como una construcción político-cultural y que se ha abierto camino desde mediados de la década de 1980, pone el "énfasis en la historicidad de las regiones, lo que lleva a considerarlas ya no como realidades fijas, sino como procesos abiertos, dinámicos, contingentes, en permanente transformación a partir de las prácticas materiales y culturales de la sociedad. Esta perspectiva, si bien no desconoce la dimensión material de la región, pone un mayor énfasis en la dimensión simbólica de la región, en su invención histórica, en las representaciones colectivas y en las relaciones de poder, en la construcción colectiva de la idea de región y en el análisis de su faceta narrativa" (Benedetti, 2009).
} 
en el proceso de constitución de la nación argentina. Este autor ha optado por utilizar el término "provincia-región", para referirse a las unidades sociopolíticas más estables que emergieron del territorio del antiguo virreinato y que se delinearon en torno a las antiguas ciudades coloniales. En ellas -y de modo particular, en Corrientes-, el predominio del capital comercial habría sido un factor relevante en la conformación del particularismo regional (Chiaramonte, 1991: 24-31).

Se nota, en cambio, la ausencia de trabajos que hayan profundizado en la evolución del proceso de regionalización del litoral durante la segunda mitad del siglo XIX, en el marco de la consolidación del Estado nacional, que conllevó la resolución del problema de la integridad territorial con la incorporación efectiva de extensas superficies que hasta entonces estaban bajo dominio indígena y la organización de los territorios nacionales. Teniendo en cuenta estos antecedentes, y partiendo del supuesto de que una región puede sufrir cambios fundamentales a lo largo del tiempo -a través de procesos de incorporación o desintegración territorial-, resulta de interés analizar las cartas escritas por Gabriel Carrasco sobre el final de la década de 1880, en momentos en que la región litoral parecía reinscribirse en el espacio a fin de dar cabida a las zonas ribereñas de los territorios nacionales de Chaco y de Formosa, la provincia de Corrientes se rediseñaba con el definitivo deslinde del antiguo territorio de las misiones, y el Uruguay y el Paraguay -guerra mediante- redefinían sus relaciones con nuestro país. Lo que en definitiva se procura, a partir del análisis del testimonio brindado por un funcionario e intelectual representativo de la elite dirigente de los ochenta, es contribuir desde una perspectiva historiográfica a la reconstrucción del proceso de regionalización de un ámbito que, décadas más tarde, y como consecuencia de una política de planificación llevada adelante desde el Estado, sería individualizado bajo el nombre de región Nordeste. ${ }^{2}$

\section{La figura del viajero experto}

Gabriel Carrasco (1854-1908)3, abogado, periodista, funcionario, legislador, docente, historiador, pero sobre todo, insoslayable estadístico al servicio del Estado, fue designado en 1888 Comisario General de la investigación Agrícola por parte de la Comisión Argentina cooperadora de la Exposición de París, con el encargo de proveer a la organización del Censo de Agricultura y Ganadería de la República.

\footnotetext{
2 Con respecto al NEA es conveniente recordar que se trata de una región eminentemente administrativa, y distinguirla de las regiones históricas que pueden coexistir en ella. Tal como ha puntualizado hace ya varias décadas Ernesto Maeder, "el NEA no constituye una región histórica, y ni siquiera una región geográfica. Es sí, un sector territorial definido del mapa de la república, que incluye, como se sabe, las provincias de Chaco, Formosa, Corrientes, Misiones y los departamentos del norte de Santa Fe, y cuya funcionalidad ha sido establecida a fin de facilitar el mejor manejo de ciertas áreas de gobierno que requieren acuerdos parciales." (Maeder, 1982: 18) Las Cartas de Carrasco de 1888, no obstante, permiten problematizar estas afirmaciones, ya que le confieren al NEA el antecedente histórico de haber sido considerado como un espacio diferenciado ya a fines del siglo XIX.

3 Para aspectos biográficos: De Marco, 1996.
} 
Carrasco pertenecía, junto a otros estadísticos de la época como Diego G. De la Fuente, Alberto B. Martínez, Emilio Lahitte y Francisco Latzina, a la que Hernán Otero ha denominado "edad del entusiasmo" censal de fines del siglo XIX. Los mencionados:

[...] constituyeron un grupo caracterizado por su permanencia, por su activa circulación en las diferentes reparticiones gubernamentales de estadística (en particular, su alternancia al frente de comisiones nacionales y provinciales y entre las áreas sociodemográficas y económicas), y por su intensa participación en diferentes registros discursivos (la cuantificación estadística, sin duda, pero también la ensayística, las obras académicas y la propaganda). Otro rasgo distintivo de la estadística del período - continúa Otero- es que las obras producidas tuvieron el sello personal y científico de sus autores. [...] La estadística de autor constituye un reflejo sintomático de la incompleta estandarización de la producción cuantitativa del período y una clave elocuente de las potenciales de notoriedad pública e intelectual que caracterizaron a los estadísticos decimonónicos en relación con sus anónimos sucesores del siglo siguiente (Otero, 2006: 217-218).

Varias de estas características se encuentran presentes en la vasta producción de Gabriel Carrasco ${ }^{4}$, quien a raíz de la referida designación realizó durante 1888 dos viajes por la región noreste o litoral del país, los que le suscitaron una serie de impresiones que quedaron plasmadas en sus Cartas de viaje (Carrasco, 1889). Al año siguiente, y como continuación de las tareas censales a las que estaba abocado, sus responsabilidades lo llevarían a realizar un nuevo periplo, esta vez a través de un itinerario que cubriría parte de la provincia de Buenos Aires, Mendoza y Chile, para culminar en Europa, en donde representaría a la Argentina en la Exposición de París. Por ello, aquellas primeras Cartas se completan con una nueva serie de Cartas de Viaje (Carrasco, 1890) ${ }^{5}$.

Dentro de aquellos variados registros discursivos utilizados por los estadísticos decimonónicos, a los que hace alusión Otero, corresponde ubicar a la obra de Carrasco dedicada a la región litoral. Se trata de un conjunto de 37 cartas, de acotada extensión (en general, no superan las diez páginas, y algunas tienen sólo cuatro), redactadas en primera instancia para el diario La Prensa de Buenos Aires, ya que como Carrasco reconocería, el poder haber hecho el viaje se lo debía a Don Adolfo Dávila, redactor de La Prensa y presidente de la Comisión del Censo Agrícola de la República. Las cartas, además de por La Prensa, fueron reproducidas in extenso por El Mensajero del Rosario, y fragmentariamente por diversos periódicos del país y del extranjero. Al año siguiente, aparecían compiladas en formato de libro.

4 Listados sobre la extensa obra de Gabriel Carrasco pueden encontrarse en: Carrasco, 1894 y Farini, 1946.

5 Este segundo libro está dedicado a la visita realizada por Gabriel Carrasco a Mar del Plata, Los Andes, Chile, la Exposición Universal de París de 1890, España, Inglaterra, Francia, Alemania, Austria, Suiza e Italia. 
El reconocimiento del terreno realizado por Gabriel Carrasco se concretó a través de dos viajes: el primero, de 37 días, entre junio y julio de 1888, y el segundo, con una duración de 25 días, en octubre de ese mismo año.

En el primer viaje, visitó las poblaciones de La Paz (Entre Ríos), Goya (Corrientes), Corrientes, Resistencia (Territorio del Chaco), Formosa, Asunción (Paraguay), Puerto la Patria (Formosa), Paso de la Patria (Corrientes), Ituzaingó (Corrientes), Posadas (Misiones), Posta del Playadito (Corrientes), Santo Tomé (Corrientes), Monte Caseros (Corrientes) y Concordia (Entre Ríos). Fue un viaje en el que recorrió "más de ochocientas leguas, navegando en cinco ríos, a bordo de diez vapores diversos, y dos ferrocarriles, sin contar una mensajería y muchos caballos" (Carrasco, 1889: 213).

En el segundo viaje, que tuvo lugar durante el mes de octubre, Carrasco retornó a los parajes ya visitados para controlar de qué manera avanzaban los trabajos censales. De extensión más breve, en ese viaje fue a Corrientes, las colonias Las Palmas, General Vedia y San Carlos (Chaco), Resistencia (Chaco), Formosa y la colonia Aquino (Formosa).

Aunque Gabriel Carrasco realizó sus viajes en función oficial, sólo tangencialmente se refiere en sus cartas a las actividades que llevó a cabo en relación con la organización del censo, a las que apenas alude, y es recién en las cartas del mes de octubre en las que se detiene a incluir algunos de los datos que se van recolectando. (Carrasco, 1889: 295 y ss.). Asume, en cambio, el rol de viajero -casi turistadeslumbrado con los paisajes y realidades que descubre en las provincias y territorios del litoral argentino.

Son varios los pasajes en que Gabriel Carrasco subraya su condición de viajero, tal como lo hace al inicio de la primera carta:
¡Otra vez en viaje!
Parece que tal fuera mi destino.
Después de haber recorrido durante siete meses la provincia de Santa Fe, hoy mi buena suerte me depara el conocimiento del litoral Argentino.
Corrientes, Resistencia, Formosa, Posadas, el paraguay y el alto Paraná son mi itinerario.
Preparo mi breve equipaje de turista: planos y mapas, libros y papel, forman su base esencial: lo demás, se encuentra en ruta o se prescinde de ello (Carrasco, 1889: 7).

Con el correr de los días y el transcurrir de las cartas, Carrasco refuerza su imagen de viajero: "En mi calidad de turista y de observador, he procurado hablar con todos, para formarme así una idea exacta del modo de pensar de esta población" (1889: 52). Destaca, además, sus cualidades como observador: "Mientras los demás se divertían, yo inspeccionaba..." (1889: 248). Su formación especial, y su experiencia 
previa recogida en anteriores tareas censales, le permiten lograr una mirada más aguda y fundamentada sobre los espacios que recorre que la que pueden llegar a forjase sus eventuales compañeros de viaje.

Además, se presenta como un viajero distinguido y un hombre de elite, pero a la vez, adaptable a las circunstancias y a la precariedad de la infraestructura del espacio que recorre. Por ello, aclara que tiene el "estómago de viajero, que en ciertos momentos embaula con igual fruición un menú de la Rotisserie Florida, que una omelette de charqui, de vizcacha, o de carpincho (...)" (Carrasco, 1889: 64).

Asimismo, se desenvuelve con las licencias propias de su condición de visitante: "Aún sin ser invitado, con el derecho que casi siempre se toma el forastero para concurrir a todas partes y no teniendo más que mi modesto traje de viajero, acudí a la casa de Gobierno (...)" (Carrasco, 1889: 127).

En la construcción de esta imagen de viajero realizada ex profeso por Carrasco a través de las cartas, alude a su historia personal y a los recuerdos de infancia, cuando en la librería de su padre Eudoro "leía con avidez las relaciones de viaje", y se presenta como un viajero permanente: "sólo tengo mi casa como puerto de descanso, como nido donde reposarme de las continuas excursiones a que mi vocación me lleva" (Carrasco, 1889: 8-9).

Ese rol que se auto adjudica es el que le hace preferir el género epistolar, un género ya utilizado por otros viajeros ilustres por esas y otras latitudes. Expresamente menciona a Mr. Peyret (Alejo Peyret) y "sus interesantes Cartas sobre Misiones" (1881), como el modelo que ha decidido imitar. (Carrasco, 1889: 5). Pero se puede recordar que también Domingo F. Sarmiento, entre otros, había escrito en forma de cartas sus Viajes en Europa, África y América, 1845-1847 (1849 y 1851, 2 vols.), y que el género epistolar contaba ya con toda una tradición vinculada a la literatura de viajes ${ }^{7}$. Además de Peyret, también los hermanos Parish Robertson, a principios del siglo XIX, habían escrito en forma de cartas sobre los mismos territorios que recorrería Carrasco al finalizar la centuria (Parish Robertson, 1950). Cabe agregar que ese género se prestaba a la publicación por entregas, que suponía la difusión a través de la prensa. Tal como ha sido apuntado:

\section{(...) no es casual que el relato de viajes haya incorporado la retórica epistolar. La carta, en su juego de distancias, propone la solución de la discontinuidad: llena un vacío. Sin embargo, la experiencia del lugar de origen, el pasado, el destinatario que}

\footnotetext{
${ }^{6}$ Nacido en Buenos Aires, y de pasado rosista y federal, Eudoro Carrasco (1824-1881) fue un activo y emprendedor vecino de Rosario, dueño de la segunda imprenta con la que contó esta ciudad, fundador y redactor de diversos periódicos y autor de estudios sobre la historia de Rosario y la región. Ocupó, además, diversos cargos en la función pública municipal y se desempeñó como diputado provincial. En ese ámbito familiar, atravesado por intereses culturales y políticos, se crió su hijo Gabriel.

7 Sobre literatura de viaje y viajeros se han llevado adelante interesantes trabajos de investigación en los últimos años, varios de ellos dedicados específicamente a viajeros argentinos del siglo XIX. Consultar, entre otros: Fernández, Geli y Pierini, 2008; Fernández y Navarro, 2011, y Bruno, 2013.
} 
allá permanece, constituyen el marco de referencia. A partir de esa experiencia previa el otro mundo adquiere sentido, se convierte en materia interpretable, sujeta a la jerarquización que la comparación impone (Ramos, 1996: 73).

Las cartas, según la explicación de Carrasco, le servían para brindar sus primeras "impresiones de viaje" sobre un espacio geográfico que sólo había llegado a apreciar a vuelo de pájaro y sobre el que aún no había podido profundizar demasiado ni de manera más exhaustiva, pero que consideraba importante dar a conocer cuanto antes. Por ello, prometía un estilo libre y espontáneo, alejado de las precisiones y acartonamientos académicos: "No se pida en mis cartas de viaje, que con la presente empiezo, la meditación del que escribe en su bufete, ni la lógica del que desarrolla una tesis. Rápidos como las impresiones recibidas; fugaces, a veces, como ellas, serán mis pensamientos (...)" (Carrasco, 1889: 15).

La elaboración de estas cartas, redactadas en primera persona, y llenas de reflexiones y vivencias personales, debe haber resultado una amena distracción para un Carrasco que por esos mismos momentos daba culminación a toda la tarea de procesamiento y análisis de datos correspondientes al censo santafesino de $1887 .{ }^{8}$

Pero a la vez, a través de las cartas se percibe el imperativo experimentado por Carrasco, sobre su responsabilidad como publicista de procurar promover el desarrollo de esos territorios periféricos: "impulsar estos progresos; hacer que ellos se verifiquen en el menor tiempo posible, he ahí la gran tarea de los escritores argentinos; he ahí el alto propósito que debemos perseguir, he ahí la mayor prueba de amor a nuestro país" (1889: 56). Por ello escribe, inclusive "robando horas al descanso del viajero" (Carrasco, 1889: 218-219), e insta a la prensa a reproducir sus cartas: "llamo especialmente la atención de cuantos lean esta carta, pidiendo a toda la prensa argentina que la reproduzca, como un medio de fomentar una importante industria" (Carrasco, 1889: 181). Es evidente la importancia que le concede Carrasco al periodismo como formador de opinión, así como el papel que se procura conferir a sí mismo como portador de una palabra autorizada e influyente. De esta manera, se termina de configurar la imagen de viajero espectable que sobre sí mismo ofrece Carrasco: "La Prensa, como diario y yo como individuo, nos consideraremos muy honrados con ser útiles para tan noble empresa (...)" (Carrasco, 1889: 212).

\section{3. “¡Población y capitales, es lo único que falta en esta tierra!”}

En la presentación del libro, Gabriel Carrasco se refiere al espacio recorrido durante sus viajes por el litoral como "bellos territorios", "tan calumniados como poco conocidos" (Carrasco, 1889: 5). Estas dos ideas sirven de eje para articular a todo el conjunto de las cartas: por un lado, las extraordinarias bellezas y recursos que esos territorios encierran; por el otro, el desconocimiento que existe sobre ellos, y que les

\footnotetext{
8 Primer censo general de la provincia de Santa Fe, 1887. 1888. Buenos Aires, Peuser.
} 
impide prosperar como debieran. Con respecto al primer punto, Carrasco es tributario de viajeros y naturalistas, como Félix de Azara, Alcide D’Orbigny, los hermanos John y William Parish Robertson, Amadeo Bompland o Alejo Peyret (a estos dos últimos, los menciona de manera explícita en sus cartas), que durante los siglos XVIII y XIX recorrieron la región, describiendo sus riquezas naturales y sirviendo como base para que en el seno de sus elites se construyera un imaginario acerca de sus potencialidades económicas y sus promisorias perspectivas (Quiñonez, 2007: 38, y Montenegro, 2013). Las expresiones de Carrasco resultan categóricas al respecto: "Quien no ha visto estas selvas, no puede formarse una idea de su espesura y grandiosidad"; se encuentran allí "tierras de fertilidad exuberante, que solo requieren un poco de trabajo para dar los más óptimos frutos" (Carrasco, 1889: 104 y 245).

Con respecto a lo segundo, Carrasco lo expresa en forma literal, al visitar Posadas: “QQué falta, pues, a esta bellísima tierra, para ser uno de los centros de progreso de la América del Sud? Le falta solamente el ser conocida (...)" (Carrasco, 1889: 157). Este conocimiento que se desea difundir está direccionado en un único y preciso sentido: Europa. Buen exponente del clima intelectual argentino decimonónico, el europeísmo de Carrasco es fuerte y no contempla la llegada de otros posibles contingentes poblacionales. Por ello, se muestra convencido con respecto a que el Censo Agrícola y Ganadero, cuyos resultados serán difundidos en la Exposición de París, "revelará a la Europa asombrada las enormes riquezas ganaderas que contiene nuestro país, de las que jamás se había levantado un inventario". Sostiene que "nuestro país, inmenso, rico, pero despoblado, necesita anticipar el tiempo de su población, facilitando a la Europa, rehenchida de habitantes, el conocimiento de sus espléndidas condiciones físicas, económicas y sociales" (Carrasco, 1889: 217-218).

En las cartas escritas durante los meses de junio y julio, Carrasco refuerza la idea del desconocimiento que existe -no sólo en el extranjero, sino también en el país- sobre la región que en ese momento concita su interés. Pero al iniciar la redacción del segundo conjunto de cartas, durante el mes de octubre, su visión se hace más general, y dedica varios párrafos a señalar la ignorancia recíproca, la incomunicación y el aislamiento en el que se encuentran las distintas partes que componen el país. Su escrito es un llamado a lograr una auténtica integración territorial de un Estado que recién entonces se está consolidando como tal: "Vivimos en un aislamiento casi completo; los habitantes de los extremos de la República, reciben tarde y mal, las noticias del centro, y éste, a su vez, poco, o muy poco conoce de lo que pasa a la distancia" (Carrasco, 1889: 219).

El destacado estadístico introduce información que sin duda ha consultado recientemente con motivo de sus estudios demográficos, para hacer resaltar la escasez de habitantes, y recuerda que estas tierras son unas de las más despobladas de todo el planeta: "La República Argentina y el Paraguay tienen igual población específica que la Siberia, el desierto helado del Asia" (Carrasco, 1889: 121). La solución, para un siempre optimista Gabriel Carrasco ${ }^{9}$, es darlas a conocer a fin de promover la llegada de población y capitales extranjeros:

9 En general, todos los escritos de Gabriel Carrasco rebosan optimismo sobre el porvenir venturoso que 
(...) esos territorios son espléndidamente bellos, encierran infinitas riquezas naturales, y están destinados por la naturaleza y por la marcha general de la civilización universal a un porvenir tan grandioso (...)

Allí, solo falta población y capitales, pero irá adquiriéndolos a medida de que desaparezcan las preocupaciones que la ignorancia ha mantenido a su respecto (Carrasco, 1889: 6).

El leit motiv se repite a todo lo largo de las cartas. Al llegar a Misiones, Carrasco exclama: “Población! ¡Población y capitales, es lo único que falta en esta tierra!" (Carrasco, 1889: 160) Y de nuevo, al llegar a Santo Tomé: “¡Todo, todo existe en esta hermosa tierra: sólo faltan capitales y brazos, para convertirla en un emporio de riqueza industrial!"' (Carrasco, 1889: 182).

Este diagnóstico, común al de otros letrados y funcionarios argentinos de la época, se nutre en el caso de Gabriel Carrasco tanto a partir de estudios y lecturas, como de la experiencia atesorada en diversas actividades y cargos en la función pública. Nacido en una de las ciudades más cosmopolitas de la República, y en trato y contacto directo con extranjeros desde su infancia, a partir de 1883 Carrasco había integrado la Comisión Nacional de Inmigración de Rosario, de la que había sido nombrado vicepresidente en 1886. Al año siguiente - y un año antes de recorrer el litoral de la Argentina-, Carrasco había llevado adelante una obra de fundamental importancia para su provincia, al desempeñarse como comisario general y director del Primer Censo de Santa Fe. Al recabar y, posteriormente, evaluar los datos censales, se había convencido de los beneficios que aportaba una corriente continua de inmigración al progreso económico y social de estas tierras. Esto se advierte en la presentación escrita de los resultados del Censo, concluida en 1888, en la que Carrasco sostiene con vehemencia: "Todos los adelantos y sorprendentes progresos que de treinta años a esta parte ha hecho la República entera, y especialmente la Provincia de Santa Fe pueden sintetizarse, resumiendo su causa en una sola palabra - la Inmigración. (...) Puede decirse con exactitud, que el progreso de nuestro país está en razón directa del número de inmigrantes que recibe". ${ }^{10}$

Por ello, al redactar durante ese mismo año sus cartas de viaje por el litoral, lo hace con la autoridad de quien conoce de lo que habla, y con el sentimiento de superioridad de quien se sabe proveniente de una región más desarrollada, en medio de un ámbito más relegado en el impulso modernizador que atraviesa el país. Es en ese carácter, que no se cansa de insistir en sus cartas sobre la necesidad de promover la llegada de inmigración y de capitales a esas regiones tan ricas en recursos naturales como abandonadas a sus solas fuerzas, apelando de paso al ejemplo santafesino que bien conoce. La comparación se vuelve drástica cuando contrapone la productividad

espera a la Argentina, sobre los beneficios que le aportará al país la inmigración y sobre la facilidad para vencer las escasas dificultades que al proceso de desarrollo pudieran presentarse. Ver: Micheletti, 2005.

10 Primer censo general: XXIV. 
santafesina al espíritu guerrero correntino: "comparé a Corrientes, manejando el fusil, con Santa Fe que empuña el arado, y pude ya darme cuenta de la razón de los progresos de la una y del letargo de la otra" (Carrasco, 1889: 42). La mención del desequilibrio existente entre ambas regiones se reitera al llegar a Ituzaingó: "se nota en estos pueblos la falta de toda industria agrícola. (...) La alfalfa se vende a mayor precio que en Santa Fe la harina! (...) Es la falta absoluta, o casi absoluta de agricultores, la que hace tan pobre a estos pueblos, fundados sobre una tierra vegetal tan rica que solo espera el más pequeño cultivo para dar abundantes frutos" (Carrasco, 1889: 140).

Para este santafesino orgulloso de los progresos que en las últimas décadas ha experimentado su provincia, que ha logrado insertarse adecuadamente en el modelo agroexportador impulsado por la elite liberal de los ochenta, Santa Fe es el ejemplo a imitar para una región que, hasta el momento, ha permanecido apartada del proceso de cambio: "Resistencia (...) no tardará en efectuar progresos tan rápidos como los que en Santa Fe son el asombro de toda la República" (Carrasco, 1889: 62). Al visitar Concordia, la referencia a la provincia modélica se reitera: "Dentro de pocos años, la producción de vinos será aquí tan enorme, como lo es relativamente la del trigo en mi querida Santa Fe" (Carrasco, 1889: 209).

La clave, para esos territorios del litoral, aún despoblados y poco productivos, es imitar a Santa Fe en su política de inmigración y colonización. Esperanzado, Gabriel Carrasco estima que "la colonización que se está operando en ellos, no tardará en transformar por completo estos territorios, como ha transformado en pocos años los desiertos del norte y oeste de Santa Fe, haciendo de ellos el paraíso de las colonias" (Carrasco, 1889: 245-246).

En este punto, cabe preguntarse el motivo por el cual Gabriel Carrasco ha dejado aparentemente afuera de la región litoral que describe a una provincia de Santa Fe que históricamente ha formado parte de esa región. Resulta claro, de primera instancia, que el recorte geográfico de las cartas está marcado por el itinerario cubierto a través de los dos viajes realizados durante 1888 -aprovechando sobre todo la vía fluvial-, en función del Censo de Agricultura y Ganadería a levantar. En esos viajes, apenas si hizo tierra Carrasco en la provincia de Santa Fe, muy probablemente debido a que los datos sobre ésta habían sido ya relevados el año anterior, de modo que resulta comprensible que la descripción de esta provincia no constituya un eje central de las cartas. Pero en un segundo análisis, y a partir de la serie de contrastes que se van intercalando en el texto entre la provincia de Santa Fe y el resto de las provincias y territorios del noreste, no parece aventurado inferir que Carrasco no se encuentra dispuesto a presentar a su provincia como formando parte de una región en la que observa tan desigual grado de desarrollo. Si el pasado parece vincular a Santa Fe con las provincias de Entre Ríos y Corrientes $^{11}$, el despegue económico alcanzado por la primera en las últimas décadas

\footnotetext{
${ }^{11}$ Se debe ser cauteloso, de todos modos, al considerar las posibles similitudes existentes entre las tres provincias del Litoral durante la primera mitad del siglo XIX. Tal como lo ha advertido Chiaramonte, durante esos años Corrientes se diferenció de Santa Fe y de Entre Ríos en cuanto a su estructura productiva más diversificada, la presencia en su sociedad de un importante e influyente sector mercantil, y su organización política más estable y compleja y sin caudillos rurales dominantes. Según este autor:
} 
parece distanciarla -sobre todo con respecto a esta última- y resulta suficiente para considerarla ajena a una región que ha sido advertida como estancada, y a la que este publicista y estadístico se ha propuesto promocionar. Hacia los años ochenta, Santa Fe se recorta como una unidad en sí misma, diversa por las peculiares características que ha adquirido gracias al exitoso modelo de colonización implementado, para una dirigencia santafesina que gusta hablar de su provincia como de la "región del trigo". ${ }^{12}$

Algunos aspectos puntuales son los seleccionados por este observador avezado para evaluar los territorios del litoral que recorre: existencia de luz eléctrica, estado general de las comunicaciones, situación de los puertos, existencia del ferrocarril, condiciones de las oficinas de correos y telégrafos, producción agrícola e industrial, calidad de las escuelas y nivel de concurrencia a las mismas, presencia de clubes y centros de sociabilidad. Gabriel Carrasco consigna con sorpresa los recientes avances que advierte en estos aspectos, pero también las grandes falencias que aún subsisten. Al resaltar los aspectos negativos, se muestra convencido del rol a cumplir por la prensa como generadora de opinión: "La misión de verdad que el periodismo impone, y el deseo de contribuir al remedio de tamaños males, aunque sea en la más humilde escala, me impele a consignar estos datos en mis cartas de viaje, para que si ellas son leídas por los que pueden ponerles remedio, lo hagan, para merecer así la bendición de los que sufren" (Carrasco, 1889: 197-198).

Para Carrasco, "el desideratum del progreso está en la facilitación de los medios de viabilidad" (Carrasco, 1889: 162), y las deficiencias de ellos en la región litoral constituyen un gran obstáculo a salvar. Con respecto al ferrocarril, el rol que le asigna es el que resulta funcional al modelo económico agroexportador, y que caracteriza a todo el sistema ferroviario que se está construyendo contemporáneamente en el resto del país: "Las actuales riquezas vegetales de estas comarcas, hoy completamente solitarias, hacen anhelar el pronto establecimiento de una línea férrea, que uniéndola a las ya existentes o en construcción, permita la fácil salida de sus productos, hacia los puntos consumidores" (Carrasco, 1889: 106).

La insistencia sobre la importancia del desarrollo de las comunicaciones se refuerza con la constatación del avance experimentado en aquellos parajes de la región que ya han logrado ser integrados al circuito nacional a través de los medios de transporte (Carrasco, 1889: 179). Gabriel Carrasco hace notar la importancia de la construcción del ferrocarril en las zonas que aún no lo tienen, tanto más necesario en aquellos territorios, como los de la provincia de Corrientes, cuya geografía pareciera

\footnotetext{
"Esta distinta conformación socioeconómica se tradujo en una distinta política frente al problema de la organización nacional, que hizo de Corrientes la piedra fundamental de las políticas antirrosistas del período". Chiaramonte, 1991: 17 y 48.

12 En 1883, otro destacado intelectual rosarino, Estanislao Zeballos, escribió el libro La rejión del trigo (sic), en el que describió la especial fisonomía sociocultural y económica que estaba adquiriendo la provincia de Santa Fe como consecuencia del proceso de inmigración y colonización. (Zeballos, 1883) El término acuñado para designar a la provincia resultó exitoso y fue reproducido por diversos autores, analistas, periodistas y gobernantes de la época. Así lo hizo el mismo Gabriel Carrasco en una de sus cartas, en la que sostuvo: "Santa Fe, es la Región del Trigo, según lo ha dicho, tan expresivamente, uno de sus hijos -Zeballos- Concordia, es la Región de la Viña (...)”. Carrasco, 1889: 211.
} 
aumentar aún más el aislamiento en el que se encuentran, debido a la presencia de los esteros del Iberá: "Si alguna provincia existe en que la locomoción ferroviaria sea más que necesaria, imprescindible, es seguramente ésta, que se encuentra aislada de sí misma, por el más impenetrable sistema hidrográfico que haya podido soñar la fantasía" (Carrasco, 1889: 227-228).

En cuanto a centros de sociabilidad, Carrasco se complace en observar que en $\mathrm{La}$ Paz, en Goya y en Formosa ya existe un Club Social, institución que en cambio -recuerdacostó mucho instalar en Rosario, su ciudad natal. Para Gabriel Carrasco, el club social de una localidad es "ese centro de reunión, a que, terminados los trabajos cotidianos, puede acudir su buena sociedad a tener un momento de contacto y de expansión" (Carrasco, 1889: 18 y 21). También destaca, cuando existen, las iniciativas de la sociedad civil de los parajes que visita, como la existencia en Goya de una sociedad popular que costea una escuela, que no cuesta nada al Estado (Carrasco, 1889: 23-24). En tanto, enuncia una crítica velada a aquellas sociedades que no han sabido organizarse armónicamente, como la de Corrientes, en donde tres clubes, el Social, el Progreso y el Porvenir, ponen de manifiesto las desinteligencias en cuestiones de política interna (Carrasco, 1889: 3738). Con motivo de las fiestas julias, Gabriel Carrasco tiene la oportunidad de asistir a la instalación en Corrientes de una nueva asociación, la Sociedad Estímulo Literario, fundada por jóvenes alumnos del Colegio Nacional. Ello le merece un elogio y una nueva comparación con Rosario que, en este caso, resulta desfavorable a la ciudad del sur santafesino, en la que el mercantilismo "domina por completo" (Carrasco, 1889: 129). Pero además, a Carrasco le interesa resaltar que en las distintas localidades que visita -incluidas las del remoto Chaco- asiste a reuniones sociales y veladas, y que en ellas se escucha música culta y se toca el piano, porque lo que busca es quitarle a la región la imagen de espacio salvaje que conserva y otorgarle una de ámbito en vías de civilizarse y civilizable, que la haga más atractiva a la colonización.

En líneas generales, se puede decir que en las cartas escritas durante el primer viaje, entre junio y julio de 1888 , predomina su admiración por las condiciones naturales de una región hasta entonces desconocida para él, a la vez que advierte todo lo que aún falta con respecto a lo que a desarrollo material se refiere, por lo que Carrasco -aún sin pretenderlo- termina resultando bastante crítico. El retorno del mes de octubre le permite realizar una apreciación más detenida sobre algunos aspectos, y se nota cierto matiz distinto en el tono de las cartas, que en esta ocasión buscan enfatizar la rapidez con la que se producen los progresos en la región, al punto de que son constatables en el escaso lapso transcurrido desde la anterior visita. En diversos párrafos, por ejemplo, destaca la existencia en la región de numerosos hornos de ladrillo en constante producción. En Resistencia escribe: "A pesar del corto tiempo transcurrido, se marcha aquí tan rápidamente, que encuentro ya mucho de nuevo" (Carrasco, 1889: 267). ${ }^{13}$ Estas

\footnotetext{
${ }^{13}$ En el Chaco, al visitar la colonia Vedia, exclama Carrasco: "Hace tres meses, estos parajes eran tan solitarios y salvajes, como un punto cualquiera del interior del Chaco al que nadie ha penetrado todavía. / Hoy, gracias a los señores Rojas, todo aquello se ha transformado. / Numerosas cabañas asentadas al pie de los bosques, dan abrigo a los colonos, que se han dedicado por completo a sus tareas agrícolas." (Carrasco, 1889: 244-245).
} 
últimas cartas, entonces, transmiten una sensación de mayor satisfacción del autor con la realidad que describe. Al avistar desde el barco la colonia Ocampo (todavía en la provincia de Santa $\mathrm{Fe}$ ) percibe los progresos operados en ella desde que la visitara un año y medio antes, gracias, en gran medida, a la construcción del ferrocarril. Los principios del liberalismo económico quedan expuestos aquí, al remarcar Carrasco el valor de la iniciativa privada y personalizarlo en la figura del fundador de la colonia: "Muchos Ocampos en la República, transformarían nuestro país en muy poco tiempo, y harían de las soledades del Chaco, de Misiones y de Santiago, emporios de progreso como el que hoy representa la colonia que él ha fundado" (Carrasco, 1889: 224). Luego, ya en territorio del Chaco, Carrasco asiste gozoso a la inauguración de la colonia General Vedia, y en la sencilla y emotiva ceremonia se oficia una misa. Carrasco es católico, pero como las tendencias secularizadoras se extienden por el país prefiere evitar los comentarios de índole religiosa e interpretar a ese acto litúrgico, más bien, como un signo de civilización y un logro más de la conquista europea de América (Carrasco, 1889: 246-247). Entusiasmado por el clima festivo que lo rodea en las incipientes colonias que visita, Carrasco brinda entre los presentes en la ceremonia por "la pronta existencia de la décima quinta provincia argentina del Chaco Austral", e inclusive se anima a proponer que el escudo, "prescindiendo de las tradiciones de sangre que colocan armas en todos los escudos, fuera en cielo azul, un arado al pie de una palmera". Casi sin proponérselo, Carrasco se convirtió así en el creador del escudo del Territorio del Chaco, que quedó establecido por un decreto de ese mismo día -12 de octubre de 1888- del gobernador Antonio Donovan.

\section{La evocación del pasado y los usos de la memoria}

El formato de cartas le permite a Gabriel Carrasco aproximarse al pasado por medio de breves apelaciones y evocaciones, en las cuales quedan entremezcladas la memoria personal, la memoria colectiva y la memoria histórica. Por ello, el género utilizado por Carrasco resulta útil para ensayar un análisis de la relación historiamemoria y, a la vez, de las dos miradas -y sus respectivos discursos- que esta última supone: la tradicional mirada interior o subjetiva, y la que, al impulso del desarrollo de las ciencias sociales, buscó depositar la objetividad en los fenómenos sociales y otorgó realidad ontológica a la conciencia colectiva. La historia articula su discurso en base a ambas y a los puentes que entre ambas existen, pero, a la vez, procura diferenciarse y distanciarse de ellas para poder construir su conocimiento. ${ }^{14}$

En las Cartas, la memoria personal o individual aflora en las reminiscencias de la infancia - que tienen por eje a la ciudad natal, Rosario- y en los recuerdos que Carrasco ha ido acumulando a lo largo de sus 34 años de vida y que, no obstante su juventud, le hacen adoptar una actitud grave, como de quien ya ha vivido mucho y cree haber alcanzado la edad madura. Por regla general, esos recuerdos son utilizados a modo de contraste, para evidenciar los progresos que ha traído consigo la llegada de la

\footnotetext{
${ }^{14}$ La problemática de las relaciones entre memoria personal, memoria colectiva e historia es trabajada
} minuciosamente por Paul Ricoeur en: Ricoeur, 2010. Se puede ver la presentación del tema en: 125-127. 
Modernidad a la Argentina. Gabriel Carrasco evoca, por ejemplo, sus primeras travesías en barco, en particular una en 1858 en una goleta a Buenos Aires, para la que tardaron ocho días en realizar el viaje de regreso (Carrasco, 1889: 13). También recuerda, al alejarse de las costas rosarinas en el barco que lo lleva a realizar su viaje de 1888, las épocas en que no había alumbrado eléctrico, y las medidas tomadas al respecto por su padre como funcionario municipal (Carrasco, 1889: 11-12). Contagiado por el espíritu positivista de la época, y con plena confianza en el progreso indefinido por el que marcha la Argentina, consigue hacer que la comparación entre el presente y el pasado de cuenta del formidable cambio operado: "Hoy, de Montevideo a la Asunción, el servicio se hace por vapores que son verdaderos palacios; y se va de Rosario a Buenos Aires en siete horas de ferrocarril! ¡Cuánto hemos adelantado!” (Carrasco, 1889: 13-14).

De sus primeros años de juventud, rememora Carrasco su ejercicio de la docencia en el Colegio Nacional de Rosario, así como sus servicios al sistema educativo, al haber recorrido y visitado más de un centenar de escuelas en Santa $\mathrm{Fe}$, y otro tanto en otras provincias (Carrasco, 1889: 22). También ocupa un lugar en las cartas el recuerdo de su más reciente desempeño como comisario general del censo de su provincia.

La evocación de la propia memoria en estos textos públicos cobra así sentido, ya que le posibilita a Carrasco mostrarse a sí mismo como un hombre de elite, de actuación relevante en el medio en que se mueve. ${ }^{15}$ Por ello, sus recuerdos, aunque personales, son considerados lo suficientemente significativos como para ser difundidos a través de estas cartas publicadas por la prensa. Es decir, que al mismo tiempo que Gabriel Carrasco da a conocer la región litoral -objetivo prioritario de las cartas-, aprovecha para reforzar su condición de hombre notable, auxiliado en este propósito por el género epistolar que ha elegido para la ocasión.

La memoria colectiva, en tanto, se cuela en diversos momentos del relato, que al ser un texto de escritura libre y no académica puede permitirse el apartarse de los cánones prescriptos por la ciencia histórica. Resulta oportuno recordar aquí que hacia la década de 1920, el sociólogo francés Maurice Halbwachs comenzó a estudiar lo que denominó "memoria colectiva", y la distinguió de la "memoria histórica". La memoria colectiva, en el sentido atribuido por Halbwachs, no se reduce al conocimiento histórico que comparte un grupo sino que, por el contrario, esta memoria es en cierto sentido ahistórica, anti-histórica. A diferencia del conocimiento histórico, que es consciente de la complejidad que encierra su objeto de estudio, la memoria colectiva simplifica, ve los acontecimientos desde una óptica única y comprometida. La conciencia histórica se focaliza sobre la historicidad de los acontecimientos: sobre el hecho de que hayan tenido lugar entonces, no ahora, que hayan nacido de circunstancias diferentes de aquellas que prevalecen actualmente. La memoria, como contrapartida, no percibe el paso del tiempo, niega la "pertenencia al pasado" de sus objetos e insiste sobre su presencia continua.

\footnotetext{
${ }^{15}$ La operación a través de la cual Gabriel Carrasco apela a la memoria para construirse a sí mismo como hombre de elite es habitual en sus escritos. Así se advierte, por ejemplo, en los Anales de la ciudad del Rosario de Santa Fe que publica algunos años después y en los que intercala su propia historia personal y familiar en la reconstrucción del pasado rosarino. (Carrasco, 1897, y Micheletti, 2013: 207-209)
} 
Según esta perspectiva, un recuerdo colectivo significativo expresa una verdad eterna o esencial para el grupo, y en general, una verdad trágica. De esta manera, la memoria colectiva queda vinculada a las preocupaciones actuales. Por ello, en lugar de ver en la memoria colectiva una manera para el pasado de ejercer su voluntad sobre el presente, Halbwachs buscó establecer de qué manera las preocupaciones presentes determinan aquello que recordamos y cómo lo recordamos. Parece producirse, además, una relación circular entre identidad colectiva y memoria colectiva, es decir, se elige centrar ciertos recuerdos, porque expresan lo que resulta importante para la propia identidad colectiva, y esos recuerdos, una vez puestos en relieve, refuerzan esa identidad (Halbwachs, 1995 y Novick, 2001: 10-14).

Algunos de estos rasgos que ofrece la memoria colectiva pueden rastrearse en las Cartas de Gabriel Carrasco, que abonan a la construcción identitaria de la región litoral. Así, por ejemplo, al llegar a la ciudad de Corrientes, Carrasco alude a las numerosas corrientes que allí forma el río, tan características del lugar, y a las que algunos correntinos atribuyen el origen del nombre de "las siete corrientes", aditamento que acompaña al de fundación de la ciudad. También evoca, en dicha ciudad, la tradición vinculada a la cruz del milagro (Carrasco, 1889: 28 y 33-34). Sostiene, además, que el trigo crece perfectamente en el norte de Corrientes y en el territorio de Misiones, basándose para ello no sólo en su propia observación, sino en los escritos de Peyret, y en "la tradición de que los jesuitas cosechaban trigo en sus misiones" (Carrasco, 1889: 173).

Debido a las características del género epistolar y a la operación rememorativa, las referencias a los sucesos del pasado argentino que introduce Carrasco, breves, están teñidas de subjetividad y carecen de perspectiva histórica, ya que aparecen cargadas de presentismo. Al visitar la tumba de Berón de Astrada recuerda al "mártir correntino" víctima de Rosas, cuyos "huesos, hechos polvo, se han refundido en la tierra que no pudo libertar!" (Carrasco, 1889: 35). En otro pasaje, al ver los ejercicios militares que realizan los alumnos del colegio nacional de Corrientes, recuerda la historia de guerras que caracterizó a la provincia, y lamenta que el espíritu militar domine todavía por completo a la juventud correntina. La misma operación de entablar un nexo entre el pasado conservado en la memoria colectiva y el presente vivenciado, la realiza al llegar a Resistencia:

Cuando se piensa que se está, como quien dice en el centro del Chaco; cuando se recuerdan las relaciones de viajes efectuados a estas regiones, y vienen a la mente, sin poderlo evitar, las reminiscencias de lecturas en que se detallan catástrofes, no se puede menos que sentir una agradable impresión, al percibir, desde lejos, las casitas esparcidas, que se van alineando en calles a medida que se penetra en el centro de la población (Carrasco, 1889: 46).

Lo mismo ocurre al llegar a la capital paraguaya: 
¡Héme, al fin, en la Asunción!

¡Cuánto anhelaba conocer a esta ciudad, célebre cuna de los dos más formidables tiranos que conoce la historia, crimen que acabó por pagar el pueblo con la más horrenda de las guerras, y con la destrucción de que hoy renace!

¡La Asunción!

Al pronunciar su nombre, se evocan en mi memoria los recuerdos de cien lecturas de mi niñez, de mi adolescencia, de mi juventud! (...)

Yo que leí cuanto se ha publicado después, desde Thompson y Mastermann, hasta Washburn, Mansilla y Garmendia: yo que tengo en mi poder, como préstamo confiado por el señor Gregorio Machain, del Rosario, documentos con la firma auténtica de Francia, y que he leído con risa o con dolor, las crónicas del literato español Ildefonso Bermejo, sobre su permanencia en estas regiones; al mirar, desde la cubierta del vapor, la histórica ciudad, no sabía darme cuenta de mis propias impresiones (Carrasco, 1889: 79-80).

La preocupación por la recuperación de la memoria histórica, por último, es sólo esporádica en estas cartas, muy alejadas del datismo puntilloso que pondría de manifiesto años después Gabriel Carrasco en sus Anales de la ciudad del Rosario (1897). Aparece, de todos modos, en algunas referencias, como en la mención de los autores y documentos históricos sobre el Paraguay que se acaban de citar, o en la alusión a un folleto publicado con motivo del centenario de la fundación de Corrientes. También se advierte el ejercicio de erudición histórica con motivo de los comentarios que le suscitan a Carrasco las inscripciones que observa en un monumento paraguayo. En este caso, la preocupación por la exactitud del dato se combina con un sentimiento de superioridad argentino que lleva a corregir a los paraguayos en el error incurrido al considerar la fecha de fundación de la ciudad de Asunción como fecha de la fundación del Paraguay (Carrasco, 1889: 94-95).

El uso de la memoria y las apelaciones al pasado tienen en Gabriel Carrasco una importante fuerza operativa. Letrado previo a la etapa de profesionalización de la historia en la Argentina, sus lecturas sobre el pasado, lejos de ser desinteresadas, están cargadas de preocupaciones presentes y orientadas a promover un cambio en dirección

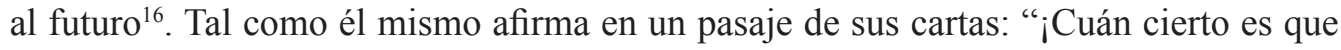
no hay hombre alguno que pueda librarse de las preocupaciones de su tiempo y de su sociedad!" (Carrasco, 1889: 29). Además, la curiosidad por el pasado en definitiva es sólo secundaria, en relación con el enorme valor que se le otorga al futuro: "Pero, basta

\footnotetext{
${ }^{16}$ Para las características con que se desarrolló la producción historiográfica santafesina entre fines del siglo XIX y principios del siglo XX me permito remitirme a: Micheletti, 2013.
} 
ya de hablar de las ruinas del pasado; tenemos al frente un porvenir, que es mucho más interesante" (Carrasco, 1889: 179).

\section{La construcción historiográfica de la región litoral}

A lo largo del texto analizado, por un lado, emergen conocimientos, datos y preconceptos que Carrasco ha ido elaborando previamente sobre los territorios que recorre, pero por otro lado, se imponen con fuerza las constataciones que va haciendo sobre el terreno, tal como él mismo no duda en confesar: "Yo también, yo que grito, quizá más alto que muchos, diciendo que los argentinos desconocemos completamente nuestro país, y que es vergonzoso que conozcamos mejor la historia y sociología de Francia o de los Romanos, que la nuestra, yo también, digo, venía con una preocupación que confieso con vergüenza para que sirva de castigo a mi ignorancia y de advertencia a los demás" (Carrasco, 1889: 29-30).

De modo que al mismo tiempo que Gabriel Carrasco va redactando sus cartas, e hilvanando sus pensamientos e impresiones recogidas en el día a día, logra dar forma a un constructo nuevo, sobre un ámbito poco explorado y conocido, y al que consigue otorgarle unidad temporal, espacial y económica al integrarlo en su relato. Ese constructo, al que en una frase citada anteriormente Carrasco define vagamente como "el litoral argentino", comprende las provincias de Corrientes y Entre Ríos, los territorios de Chaco, Formosa y Misiones, e inclusive, parte del Paraguay. Ese litoral queda articulado gracias al río que le da forma: "El Paraná, es el gigante que se extiende en la República Argentina, asemejando en su corriente el gran sistema circulatorio de un cuerpo geográfico" (Carrasco, 1889: 188).

Cabe hacer aquí un paréntesis, para reflexionar acerca del papel jugado por los intelectuales en la tarea simbólica de construcción de las regiones. Tal como ha señalado Pierre Bourdieu, en la búsqueda de los criterios “objetivos" de la identidad regional, no se debe olvidar que esos criterios "constituyen el objeto de representaciones mentales; es decir, de actos de percepción y de apreciación; de conocimiento y de reconocimiento en los que sus sujetos involucran sus intereses y sus conjeturas (...)" (Bourdieu, 1995: 315). Al pensar en el proceso de regionalización, entonces, no debe perderse de vista que:

El discurso regionalista es un discurso de ejecución que trata de imponer como legítima una nueva definición de las fronteras y a hacer, conocer y reconocer la región así delimitada contra la definición dominante (...) El acto de categorización, una vez que ha logrado hacerse reconocer o que es ejercido por una autoridad reconocida, ejerce por sí mismo poder; las categorías "étnicas" o "regionales" (...) instituyen una realidad usando del poder de revelación y de construcción ejercida por la objetivación dentro del discurso (Bourdieu, 1995: 317). 
A partir de estos postulados, podemos evaluar el rol de autoridad pretendido por Carrasco a fines del siglo XIX, al procurar incluir dentro de la región litoral a territorios que recién por entonces se estaban incorporando de manera efectiva al Estado Argentino, como el Chaco y Formosa, o al soslayar la consideración de la provincia de Santa Fe como formando parte de esa misma región. Sus intentos por llamar la atención de la prensa y de los poderes públicos sobre la necesidad de conocer y de promover esa parte noreste del país, además, ayudan a explicar mejor el discurso de regionalización que le imprime.

A la vez, puede advertirse que en la idea de región litoral que construye Gabriel Carrasco, y más allá de esa unidad discursiva que consigue otorgarle a través de sus cartas, cada una de las provincias y territorios que la integran conservan un perfil histórico y geográfico peculiar, así como una función a cumplir en el futuro.

Corrientes es la provincia de la región con mayor protagonismo en el devenir histórico argentino. Es "la provincia heroica que, después de haber dado a la historia un San Martín, el primer capitán americano, y un Cabral, el primer soldado raso a quien se haya elevado una estatua, ha sido la que combatió con más valor y sacrificios en favor de la libertad" (Carrasco, 1889: 125). Por ello, al llegar por primera vez a su ciudad capital, Gabriel Carrasco se refiere a ella como "la histórica Corrientes" (Carrasco, 1889: 27). Más tarde, al navegar frente a las costas de Yapeyú, Carrasco mira "con un sentimiento de veneración" a ese pueblo, cuna de "una gloria tan pura" (Carrasco, 1889: 193).

Sin embargo, tal como políticos e intelectuales correntinos de la época reclaman, esta provincia ha quedado relegada o postergada en las políticas promovidas desde el Estado nacional (Quiñónez, 2012 y 2008). Carrasco observa en la arquitectura de su capital las evidencias de "muchos años de estancamiento" y la consecuencia de las "conmociones internas", ya que la ciudad "se resiente aún de un estado de cosas que, a fuerza de ser anormal, habíase convertido en el modo de ser de la población" (Carrasco, 1889: 32 y 37). Entre líneas se descubre la imagen negativa que Gabriel Carrasco se había previamente forjado sobre Corrientes, debido a sus "luchas domésticas" y al papel que le tocó desempeñar en la etapa de las guerras civiles: "Los correntinos, ese pueblo heroico que durante cincuenta años ha vivido envuelto entre las guerras civiles, saben demasiado bien el camino de los campos de batalla, conocen cómo se pelea, y se muere por la patria y por la libertad y lo único que no saben es cómo se maneja un arado, y de qué manera se funda la prosperidad del país por medio del trabajo" (Carrasco, 1889: 42).

Es decir, que si bien Carrasco le reconoce a Corrientes su rol de provincia histórica y su aporte al proceso histórico nacional debido a su lucha contra el rosismo, interpreta que ese temperamento bélico es causa de su atraso, y obstáculo importante a remover para poder ubicarse en la senda del futuro. En otra oportunidad, agrega: “¡Felizmente, Corrientes no tiene más cañones! Sobra con los que ha tenido y que por desgracia ha empleado en revoluciones durante los últimos años!" (Carrasco, 1889: 128). E insiste, más adelante, que ese pueblo "recién despierta del letargo en que lo han tenido sumergido sus continuas revoluciones" (Carrasco, 1889: 228-229). Por fin, 
Carrasco cree descubrir signos de reactivación: "se ven señales de una vida que parecía estaba estancada", aunque todavía "todo está por hacer" (Carrasco, 1889: 43). Pero como contrapartida, Carrasco debe reconocer que el espíritu patriótico palpita allí más fuerte que en la fenicia Rosario, y que las fiestas patrias se celebran con mayor devoción y concurrencia. Si no en el aspecto económico, en el sentimiento de nacionalidad Corrientes parece aventajar a la ciudad en la que nació el autor de las cartas (Carrasco, 1889: 126-127).

Un siempre europeísta Gabriel Carrasco se esfuerza por encontrar y describir como blanca a la población correntina ${ }^{17}$, e ingenuamente manifiesta los prejuicios que abrigaba en ese sentido:

Yo creía, en fin, que en Corrientes dominaba, etnológicamente, la raza americana-española, pura, o apenas mezclada con la sangre del mediodía de la Europa (...)

Me engañé, de medio a medio.

Tipos bellísimos, de rostro ovalado, de ojos rasgados, llenos de inteligencia; cabezas cubiertas de cabellos castaños o rubios, y mejillas sonrosadas o pálidas, eran las que predominaban en las salas de la escuela.

¡Oh, civilización me dije! ¡Cuánto puedes!(...) (Carrasco, 1889: 30)

Los rasgos racistas y elitistas de Carrasco se acentúan más todavía cuando afirma que "la única sombra, en Corrientes, es el idioma guaraní" utilizado de modo permanente por la clase baja, "de manera que las comunicaciones intelectuales, el primero y más importante de los medios de progreso, o falta, o está muy debilitado" (Carrasco, 1889: 44).

De todos modos, y a pesar de los signos de atraso que aún subsisten en Corrientes, Carrasco cree descubrir un cambio, en sintonía con el empuje que el modelo liberal de la generación del ochenta le ha impreso al país. Por eso, la perspectiva que se avizora para el futuro de la capital correntina es promisoria (Carrasco, 1889: 44).

El Chaco, en tanto, es la tierra que parecía indómita y que se ha doblegado al avance de la civilización. Es el recuerdo de la América india, vencida y ganada para el progreso. Y también es la tierra mal conocida y calumniada. Al llegar allí, haciéndose eco de la memoria colectiva, lo embarga la sensación de saberse en "territorios, cuyo solo

\footnotetext{
${ }^{17}$ Para Gabriel Carrasco -según quedó expresado en sus estudios estadísticos- la presencia del inmigrante europeo tenía un efecto regenerador sobre la base de la población nativa. A su entender, la antigua raza criolla, mezcla del español y del indio, estaba "siendo ventajosamente reemplazada por los hijos de europeos." Miraba con esperanzas a la nueva raza en formación en la provincia de Santa Fe, producto de la unión de los inmigrantes extranjeros con las mujeres argentinas y, apelando al darwinismo en boga por entonces, la definía como una "raza nueva y vigorosa que, en virtud de las leyes de la selección natural, posee las ventajas de sus progenitores, sin heredar sus inconvenientes". Primer censo general: LV.
} 
nombre parece que impone horror -jel Chaco!" (Carrasco, 1889: 51). Pero enseguida, Carrasco reacciona contra el imaginario que se ha formado la sociedad argentina sobre ese territorio, y se respalda en la evidencia aportada por la propia experiencia, admitiendo el "contraste entre los hechos y las ideas que uno tiene preconcebidas respecto al Chaco": "las condiciones de vida son aquí infinitamente mejores de lo que la exaltada fantasía se imagina al solo nombre ¡el Chaco!” (Carrasco, 1889: 51 y 55). Y para sostener su afirmación, señala que el calor, aunque intenso, no agobia, y que allí crecen y se adaptan toda clase de cultivos y ganados. También observa que existe ya un núcleo de sociabilidad, que anima a creer en el creciente progreso de esos territorios. En definitiva, sintetiza Carrasco, "el Chaco es mucho mejor de lo que se cree" (Carrasco, 1889: 57).

La impronta del indio es fuerte en el pasado chaqueño. Sin embargo, Carrasco en parte invisibiliza esa presencia al considerar a esos territorios como "desiertos" hasta poco antes: "ver cómo nuestra civilización ha penetrado en los antes desiertos territorios del Chaco, es la más íntima satisfacción que legítimamente puede experimentar nuestro patriotismo" (Carrasco, 1889: 53). También emerge aquí su europeísmo, al entusiasmarse con el proceso inmigratorio que se ha iniciado y al apreciar de manera positiva el avance cultural extranjero: “¡Una china cordobesa, sirviéndose familiarmente del idioma inglés en el Chaco! Esto solo demuestra cuánto ha cambiado nuestro país y cuánto puede confiarse en sus progresos" (Carrasco, 1889: 54). En estas expresiones, Carrasco comparte la imagen -extendida a fines del siglo XIX- del Chaco "como un "desierto verde", un espacio sin historia, materializado sólo recientemente, gracias al proceso de apropiación llevado adelante por las expediciones enviadas por el Estado nacional y a la incipiente política de colonización. Por ello, más que pasado, el Chaco es presente y, sobre todo, futuro (Leoni, 2005).

En otros pasajes de sus cartas, en cambio, Carrasco sí reconoce la presencia indígena, a la que en su afán propagandístico se esfuerza en presentar como mansa y sumisa (Carrasco, 1889: 57). Demuestra, además, atisbos de humanitarismo, cuando se queja por la matanza reciente de indios no belicosos: "Pero el hecho serio es que, sin ser absolutamente necesario, y sin que lo impusieran las necesidades de la guerra, ha habido allí una destrucción de indios que no podían considerarse como enemigos, porque no hacían ya resistencia." Aunque en realidad, más que un sentimiento de conmiseración hacia esa gente, en este Carrasco atento a la construcción del nuevo orden social domina la idea de aprovechar al elemento aborigen para transformarlo en una fuerza productiva:

(...) el indio de estas regiones, el toba, el guaycurú, el vilela, son eminentemente civilizables, y apropiados para toda clase de trabajos.

Estos indios no son como los antiguos y temibles pampas, terror de nuestras fronteras del sud, que tenían buenos caballos, y efectuaban sangrientos malones, sin reducirse jamás al trabajo. Son, por el contrario, naturalmente pacíficos, no tienen 
caballos, viven en los bosques de los productos espontáneos del suelo, y desde el momento que se les toma y da trabajo, son los mejores peones que existen en todos estos territorios (Carrasco, 1889: 132-133).

De la lectura del texto de Carrasco parece desprenderse que es sólo debido a esa ductilidad del indio chaqueño para el trabajo que "la destrucción de los indios no está, pues, justificada, bajo ningún concepto" (Carrasco, 1889: 133). Todo un símbolo -que Carrasco celebra- es la presencia del cacique Chacarero en una fiesta a la que asiste. Se trata de un sujeto que, luego de haber peleado valientemente durante años, "ha concluido por convertirse a la civilización y hacerse amigo de los cristianos, y que se consuela de la abdicación de su reino, sirviendo de capataz a sus antiguos súbditos, que se ocupan en las faenas agrícolas" (Carrasco, 1889: 256-257); es la imagen de la América india derrotada y redimida, y ganada para el modelo económico liberal de los ochenta.

Gabriel Carrasco demanda la sanción de un decreto que declare a Resistencia de derecho - para que deje serlo sólo de hecho- como la capital del Chaco, y estima que esa simple medida gubernamental ayudaría a que la ciudad adelantara más rápidamente. También para el Chaco, como para Corrientes, se proyecta un futuro de grandeza, gracias a sus importantes recursos naturales: "Estos territorios son de una fertilidad verdaderamente asombrosa, como lo demuestra su vegetación. Una vez que el ferrocarril permita las explotaciones agrícolas, el Chaco se transformará rápidamente en un gran emporio de producción en que el tabaco y todos los vegetales más notables de la zona tropical abastecerán un comercio importantísimo" (Carrasco, 1889: 49). "La República tiene en el Chaco una reserva inagotable de productos de alto precio, y en un futuro (...) el Chaco Austral será una provincia argentina de tanta población, y de más importancia que algunas de las que hoy llevan ese título" (Carrasco, 1889: 249).

Formosa "es un pueblo que ha adelantado muchísimo en los últimos años" (Carrasco, 1889: 116). Tierra que sólo de manera reciente ha sido realmente incorporada a la nacionalidad argentina (en 1876 se firmó el tratado de límites con el Paraguay, y en 1879 fue fundada Villa Formosa), puede no obstante mostrar que en ella se celebran "dignamente" las fiestas patrias, tal como lo comprueba Gabriel Carrasco al pasar por ella durante los preparativos de las fiestas julias.

Dentro de la región litoral que construye Carrasco, Formosa es el ámbito en el que el pasado lejano no existe, de modo que la dimensión temporal se mueve entre un tenue pasado-presente, un presente y se proyecta hacia un venturoso futuro. Al pasar por puerto Expedición, por ejemplo, Carrasco recuerda que su nombre se debe a la expedición realizada por el general Benjamín Victorica en 1884, sólo cuatro años antes del viaje narrado en la cartas.

En cuanto a Posadas, en el Territorio de Misiones, "es uno de los pueblos más pintorescamente situados de la costa de nuestro gran río” (Carrasco, 1889: 147), que trae, además, el inevitable recuerdo de las misiones jesuíticas que se desparramaban por el extremo más noreste del país. El católico Gabriel Carrasco rescata la obra de los jesuitas 
y se refiere a las Misiones como una "región tan bella como calumniada". Al recorrer la zona, puede apreciar que "los jesuitas han sido hombres muy sabios y muy prácticos", lo que se evidencia en la elección que hicieron de esos ricos territorios para establecerse y en los lugares estratégicos en los que ubicaron sus pueblos. A pesar de esta valoración positiva, a Carrasco se le descuelga, tal vez por influjo de la literatura de la época, una alusión al "poder feudal" que construyeron (Carrasco, 1889: 155-156). Pero no busca ser crítico hacia ellos quien proviene de una provincia en la que los jesuitas continúan teniendo un gran prestigio a fines del siglo XIX a través del Colegio de la Inmaculada de Santa Fe, juicio en el que coincide otro autor rosarino de la época allegado a Carrasco, Pedro Alcácer (Alcácer, 1889: 145-146). Junto a las ruinas del pueblo de Apóstoles en la provincia de Corrientes, Carrasco emite un juicio de valor sobre el proceso que derivó en la destrucción de las misiones: "Estos restos de antiguas ruinas, se contemplan dolorosamente. Ha existido allí una civilización que desapareció, no por la acción del tiempo, sino por la perversidad de los hombres: las antiguas misiones, obra colosal de paciencia, de ingenio y de trabajo, han caído a impulso de la barbarie que llevó hacia ellas la desolación, el saqueo y la ruina" (Carrasco, 1889: 172).

Misiones es, entonces, "la antigua perla de las fundaciones jesuíticas, que la furia de la guerra civil sacrificara en holocausto a la barbarie." (Carrasco, 1889: 228) Pero afortunadamente, al igual que sucede con los otros territorios de la región, el futuro de Misiones resulta auspicioso: "Misiones empieza a dar también su nota armónica en el concierto de los progresos de la Argentina, en el cual hasta ahora había permanecido muda" (Carrasco, 1889: 159).

Finalmente, el Paraguay es para un argentino de los ochenta, antes que nada, el recuerdo de que ese pueblo ha sido "víctima de la más cruenta de las guerras" (Carrasco, 1889: 93). Ya al navegar su río, la memoria de la guerra se hace apremiante: “ ¡El Paraguay! El río que da nombre a la nación que, pobre, encerrada, desconocida, luchó durante cuatro años en guerra gigantesca contra tres naciones unidas! El Paraguay! ¡Cada uno de sus ríos, de sus esteros, de sus arroyos, fue teatro de alguna sangrienta carnicería, o de una catástrofe!" (Carrasco, 1889: 72-73).

En la ciudad de Asunción, los vestigios de la guerra emergen a cada paso: "La guerra desastrosa que arruinó a esta República, y que convirtió casi, a la Asunción en un montón de escombros, aún hace conocer las señales de su paso. Es así como a primera vista se nota la falta completa de administración e instituciones urbanas" (Carrasco, 1889: 83).

Paraguay es, además, para una Argentina decimonónica que presume de su liberalismo, el recuerdo de la tiranía de Gaspar Rodríguez de Francia y de los dos López. Carrasco comparte la visión historiográfica hegemónica por esos años en la Argentina, que condena a Francisco Solano como el responsable de haber arrastrado a su nación a la destrucción total (Baratta, 2014): "En la plaza de armas, se eleva una columna coronada por una estatua de la Libertad, que más que obra de arte, puede considerarse como un simple recuerdo de la deidad que durante tantos años ha estado ausente de estas comarcas." (Carrasco, 1889: 94) Similares reflexiones suscita la travesía en barco frente 
a "la histórica Humaitá, la Sebastopol americana": "Contemplé entristecido aquellas ruinas. Allí, durante mucho tiempo, la nación paraguaya se defendió con una heroicidad de que la historia presenta muy pocos ejemplos, y empleó su valor para sostener al más bárbaro de los tiranos!" (Carrasco, 1889: 122).

Por eso, la imagen de Paraguay que construye Carrasco se compone de dos ejes: por un lado, el pasado oprobioso que la guerra consiguió derribar, por otro lado, un presente esperanzador, gracias al poder de regeneración que tuvo la guerra y al cambio de gobierno que sobrevino tras ella:

El Paraguay ha adelantado más desde la época de la guerra hasta hoy, que lo que progresó desde el descubrimiento hasta la muerte de López. (...)

Si la guerra, pues, fue un mal horrendo, hay que convenir en que ese mal ha originado grandes bienes, pudiendo aquella compararse a la cauterización de una llaga -la tiranía- que ocasiona horrendos dolores al operarse, pero que asegura en el futuro la salud y la vida. (Carrasco, 1889: 123-124)

Debido a ese pasado nefasto, Paraguay es, también, el vecino sumido en el atraso, para un argentino orgulloso del crecimiento sostenido experimentado por el propio país. Por eso, los comentarios de Carrasco sobre el Paraguay pueden parecer entrometidos, pedantes y hasta soberbios. Carrasco, en su rol de observador extranjero, se considera con derecho a opinar, criticar, aconsejar y reconvenir a la nación hermana: “QQué diferencia, pensé para mí mismo, entre la Asunción, en que obligan a los pasajeros a bajar en bote, pudiendo hacerlo por el muelle, sólo para que los boteros ganen, y Buenos Aires, en que el gobierno hace desembarcar por su cuenta pagando su lanchaje, a todos los inmigrantes que llegan al país!" (Carrasco, 1889: 80-81).

Gabriel Carrasco realiza un reconocimiento de Asunción con la avidez de un antropólogo avant la letre frente a una cultura primitiva. Sostiene que en "el aspecto puramente americano, sus costumbres, su manera de ser, (...) se prestan a profundos estudios sociológicos" (Carrasco, 1889: 89). Las comparaciones con la situación argentina sólo sirven para mostrar el escaso desarrollo paraguayo, que no ha llegado a ser revertido por la modernización incipiente:

Quien pretendiera juzgar a la Asunción por el modelo de las ciudades modernas de la República Argentina u Oriental, cometería el error del que aplicara a un clima tórrido las modas y costumbres de las regiones frías de la Europa.

La Asunción, es de cuantas ciudades he visto en estas regiones, la más original.

Hay en ella una mezcla de lo moderno, y de lo antiguo; de 
las costumbres más refinadas de la civilización, con las originadas por una sociedad primitiva, o inculta, que llaman poderosamente la atención (Carrasco, 1889: 82).

El sentimiento de superioridad emerge a cada rato durante la estancia en Asunción: "Un Alvear, en dos o tres años de trabajo, haría de la Asunción una de las más bellas ciudades de esta parte de América" (Carrasco, 1889: 89).

Pero a pesar de todas las notas discordantes de atraso, también el Paraguay, por su belleza natural, por la benignidad de su clima, está llamado para Carrasco a un porvenir de grandeza junto con los territorios del litoral argentino que ha recorrido. La actual administración permite abrigar expectativas de cambio: Carrasco refiere que en su visita ha podido conocer al presidente, el general Escobar, y al ministro de Hacienda, Decoud, y que ambos le han causado buena impresión y confianza en que llevarán al Paraguay por el camino indicado.

Por último, el Uruguay. Si bien no forma parte del itinerario de viaje de Gabriel Carrasco y por ello aparece relegado en la región litoral que se construye a través de las cartas, la navegación por el río que lleva su nombre ayuda al autor a recordar los nexos que históricamente han vinculado y también enfrentado a las dos márgenes del Plata. En dichas márgenes se encuentran "dos naciones que durante tanto tiempo se han mirado con prevención." Así, para Carrasco, el estuario del Río de la Plata: "tiene a su extremidad, separadas por su corriente, pero mirándose a través del espacio y de la historia, a las dos grandes y bellas ciudades del Plata - Montevideo y Buenos Aires" (Carrasco, 1889: 188-189).

\section{Consideraciones finales}

Las Cartas de viaje de Gabriel Carrasco, una de las obras menos citadas y conocidas de este autor, se nos revelan como una singular muestra de la literatura de viajes producida por los hombres de la elite argentina de fines del siglo XIX que se aventuraron por las regiones más periféricas de nuestro país, y que incluye otras obras más renombradas, como Una excursión a los indios ranqueles (1870), de Lucio V. Mansilla, o como la trilogía compuesta por Viaje al país de los araucanos (1880), La rejión del trigo (1883) y A través de las cabañas (1888), de Estanislao Zeballos. Al igual que Una excursión o Viaje al país, las Cartas analizadas se caracterizan por ir al encuentro de la barbarie, de lo primitivo, de lo que sobrevive en estado natural, y en este sentido se distancian del más canónico relato del viaje a Europa o a Estados Unidos preferido hacia la misma época por otros letrados, como Domingo Sarmiento, Miguel Cané, Eduardo Wilde o Paul Groussac, entre otros, o como el mismo Carrasco en la serie de Cartas (Carrasco, 1890) que dan continuación a éstas.

A través de su itinerario y de su relato, Carrasco nos brinda un testimonio excepcional sobre la región litoral o nordeste del país, en tanto que ofrece la visión de un intelectual argentino finisecular sobre un espacio que hasta entonces había llamado 
preferentemente la atención de viajeros extranjeros. Aporta, a la vez, a la reconstrucción histórica del proceso de regionalización de ese espacio.

Al sopesarse las características que dan forma a la región litoral construida por Carrasco, puede convenirse en que en ella la historia, el pasado más o menos glorioso, la cultura material y los atisbos de civilización que el autor cree descubrir a su paso, sólo constituyen una parte de su realidad, y no precisamente, la más destacable. Puede advertirse, asimismo, que en esos aspectos se deja notar la ausencia o escasez de elementos cohesionadores, ya que en definitiva no parece haber un pasado en común que integre a esos distintos espacios territorianos y provinciales. El relato, que pretendía ser de conjunto, va desgranando y desagregando rasgos particulares de la historia de cada uno de éstos, que dificultan visualizarlos como un todo.

Es, en cambio, en la naturaleza pródiga que admira al Carrasco viajero y en el futuro de grandeza que se avizora, que el autor de las Cartas encuentra la nota más sobresaliente de la región litoral, así como el elemento que la aglutina. Son el clima benigno, el cultivo fácil, la adaptabilidad de las diversas especies vegetales, los bosques y ricas maderas del Chaco, la tierra roja y ferrosa de Misiones, las vides de Concordia, las plantaciones de tabaco y yerba mate, las industrias nacientes, y hasta la abundancia de yacarés -utilizables para la industria del cuero-, los que logran convencerlo de las ventajas naturales de la región y de su porvenir próspero, una vez que logre insertarse en el circuito productivo nacional y ocupar el rol relevante que está llamada a desempeñar, como unidad productiva, en el conjunto de la economía del país.

Gabriel Carrasco sueña despierto con ver esa tierra casi virgen, transformada por la civilización y el trabajo, y proyecta hacia el futuro la convicción que comparte con su generación sobre el destino que espera a la Argentina: “(...) esos progresos que veo cuando cierro mis ojos y lanzo la imaginación a los tiempos del futuro, cuando la Argentina sea la más colosal nación de América, y cuando cien millones de hombres activos, industriosos, inteligentes y morales, pueblen estas ciudades en que hoy a través de las olas del gran río, pueden a veces en el oscuro silencio de la noche, oírse los rugidos de las fieras en los bosques del Chaco" (Carrasco, 1889: 30).

En definitiva, y desde una perspectiva más amplia, estas Cartas permiten apreciar las expectativas que intelectuales y políticos de la dirigencia liberal decimonónica abrigaban, con respecto al progreso de las regiones más periféricas y relegadas del país, a la vez que la excesiva confianza que depositaban en sus propios trabajos de estadísticos y publicistas como motores de la modernización procurada. La situación de atraso socioeconómico, y las dificultades para el desarrollo de las vías de comunicación con las que esos territorios litorales recorridos en 1888 por Gabriel Carrasco se mantuvieron a lo largo de la historia argentina, marcan por cierto un límite de importancia a su voluntarismo y optimismo. 


\section{Referencias bibliográficas}

Fuentes

Alcácer, P. 1889. Compendio de Historia Argentina. Desde el Descubrimiento de América hasta nuestros días, Rosario, Olivé, Tomo I.

Carrasco, E. y G. 1897. Anales de la ciudad del Rosario de Santa Fe. Con datos generales sobre Historia Argentina, 1527-1865, Buenos Aires, Peuser.

Carrasco, G. 1889. Cartas de viaje por el Paraguay, los territorios nacionales del Chaco, Formosa y Misiones y las provincias de Corrientes y Entre Ríos, Buenos Aires, Peuser.

Carrasco, G. 1890. Cartas de Viaje. Del Atlántico al Pacifico y Un argentino en Europa, Buenos Aires, Peuser.

Carrasco, G. 1894. Bibliografia y trabajos públicos, Buenos Aires, Imprenta, Litografía y Encuadernación de Jacobo Peuser.

Parish Robertson, J. y Parish Robertson, W. 1950. Cartas de Sud-América, Buenos Aires, Emecé.

Primer censo general de la provincia de Santa Fe, 1887. 1888. Buenos Aires, Peuser.

Zeballos, E. 1883. Descripción amena de la República Argentina, Tomo II: La rejión del trigo, Buenos Aires, Imprenta de Jacobo Peuser.

\section{Bibliografia}

Baratta, M. V. 2014. "La Guerra del Paraguay y la historiografía argentina". En: Historia da Historiografia, Ouro Preto, $N^{\circ} 14$, pp. 98-115. On line. Doi: 10.15848/ hh.v0i14.614

Benedetti, A. 2009. "Los usos de la categoría región en el pensamiento geográfico argentino". En: Scripta Nova, Universidad de Barcelona, vol. XIII, No 286. On line. http://www.ub.es/geocrit/sn/sn-286.htm

Bourdieu, P. 1995. "La identidad y la representación. Elementos para una reflexión crítica sobre la idea de región", Primera de dos partes. En: Ciencia ergo sum, Universidad Autónoma del Estado de México, vol. 2, № 3, pp. 313-318.

Bruno, P. 2013. "Estados Unidos como caleidoscopio. Ensayo sobre las observaciones de viajeros y diplomáticos argentinos del fin de siglo". En: Revista Complutense de Historia de América, Madrid, Universidad Complutense de Madrid, vol. 39, pp. 23-38.

Chiaramonte, J. C. 1991. Mercaderes del Litoral. Economía y sociedad en la provincia de Corrientes, primera mitad del siglo XIX, México - Buenos Aires, FCE.

De Marco, M. A. (h.). 1996. Gabriel Carrasco, Rosario, Editorial Municipal.

Farini, J. 1946. "Bibliografía de los miembros de número de la Academia Nacional de la Historia. José Gabriel Carrasco". En: Boletín de la Academia Nacional de la Historia, tomo XIX.

Fernández, S.; Geli, P.; Pierini, M. (Comps.). 2008. Derroteros del viaje en la cultura: mito, historia y discurso, Rosario, Prohistoria Ediciones. 
Fernández, S.; Navarro, F. 2011. "La pampa transformada. La rejión del trigo de libro de viaje a catálogo de mudanzas". En: Fernández, Sandra; Navarro, Fernando (Comps.). Scribere est Agere. Estanislao Zeballos en la vorágine de la modernidad argentina, Rosario, La Quinta Pata \& Camino Ediciones.

Halbwachs, M. 1995. "Memoria colectiva y memoria histórica”. En: Revista Española de Investigaciones Sociológicas (Reis), Madrid, Centro de Investigaciones Sociológicas, No 69, pp. 209-219.

Leoni, M. S. 2005. 'Los usos del pasado en 'el desierto verde'. Historia y construcción de identidades en el territorio nacional del Chaco". En: X Jornadas Interescuelas / Departamentos de Historia, Septiembre 20-23, 2005, Rosario.

Maeder, E. 1982. "La investigación y la enseñanza de la historia regional”. En: Res Gesta, Rosario, Instituto de Historia, Fac. de Dcho. y Cs. Sociales del Rosario, UCA, No 12, pp. 15-24.

Micheletti, M. G. 2005. "Gabriel Carrasco frente al inmigrante: la confianza en la asimilación espontánea del elemento extranjero". En: Estudios Migratorios Latinoamericanos, Buenos Aires, CEMLA, No 57, pp. 367-398.

Micheletti, M. G. 2013. Historiadores e historias escritas en entresiglos, Buenos Aires, Lumiere.

Montenegro, A. B. 2013. "Los intelectuales correntinos y la construcción de un imaginario territorial a fines del siglo XIX". En: XIV Jornadas Interescuelas / Departamentos de Historia, Departamento de Historia, Fac. de Filosofía y Letras, UNCuyo, Octubre 2-5, 2013, Mendoza.

Novick, M. 2001. L'Holocauste dans la vie américaine, Paris, Gallimard.

Otero, H. 2006. Estadística y nación: una historia conceptual del pensamiento censal de la Argentina moderna, 1869-1914, Buenos Aires, Prometeo.

Quiñonez, M. G. 2007. Elite, ciudad y sociabilidad en Corrientes. 1880 - 1930, Corrientes, Moglia Ediciones.

Quiñonez, M. G. 2012. "Contextos de producción, representaciones del pasado e historiografía en Corrientes (1880-1940)”. En: Laguarda, P.; Fiorucci, F. (Eds.) Intelectuales, cultura y politica en espacios regionales de Argentina (siglo XX), Rosario, Prohistoria - EdUNLPam.

Quiñonez, M. G. 2008. “Corrientes, de los sacrificios a la postergación. Las condiciones de producción de la historiografía correntina a fines del siglo XIX”. En: XXVIII Encuentro de Geohistoria Regional, IIGHI-CONICET, Agosto 28-30, 2008, Resistencia.

Ramos, J. 1996. "Entre otros: Una excursión a los indios ranqueles de Lucio V. Mansilla". En: Ramos, Julio, Paradojas de la Letra, Caracas, Excultura.

Ricoeur, P. 2010. La historia, la memoria, el olvido, Buenos Aires, Fondo de Cultura Económica. 
